\title{
Spontaneous Remission of Paroxysmal Dystonia Coincides with Normalization of Entopeduncular Activity in $d t^{\mathrm{sz}}$ Mutants
}

\author{
Mustapha Bennay, Manuela Gernert, and Angelika Richter \\ Department of Pharmacology, Toxicology, and Pharmacy, School of Veterinary Medicine Hannover, \\ 30559 Hannover, Germany
}

Recent studies have shown a dramatically decreased spontaneous discharge rate of entopeduncular neurons in a unique animal model of idiopathic paroxysmal dystonia, the $d t^{\mathrm{sz}}$ mutant hamster. These changes were found in animals at the age at which the most marked expression of dystonia is usually observed. In this rodent model, the age-dependent disappearance of stress-inducible dystonic attacks at an age of $\sim 10$ weeks allows investigations of the relevance of pathophysiological changes for the occurrence of dystonia by ontogenetic studies. Therefore, we examined the entopeduncular activity by extracellular single unit recordings in groups of $d t^{\mathrm{sz}}$ mutants and nondystonic control hamsters at 17-22 weeks of age. In contrast to recent findings, after the complete remission of dystonia, the mean discharge rate of entopeduncular neurons in $d t^{\text {sz }}$ mutants $(28.1 \pm 1.2$ spikes/sec) was similar to that of age-matched nondystonic control hamsters (30.8 \pm 0.9 spikes/ $\mathrm{sec})$. Thus, the disappearance of paroxysmal dystonia is accompanied by a normalization of the entopeduncular activity in $d t^{\text {sz }}$ mutants. The present data clearly demonstrate the fundamental importance of a decreased basal ganglia output for the expression of paroxysmal dystonia.

Key words: animal models; basal ganglia; dyskinesia; dystonia; entopeduncular nucleus; movement disorders; single unit recordings
The dystonias are a group of serious movement disorders characterized by involuntary co-contractions of opposing muscles. It has been suggested that permanent dystonias and paroxysmal dyskinesias, which include both dystonic and choreoathetotic symptoms, are based on a reduced inhibitory output of the basal ganglia (Wichmann and DeLong, 1996; Vitek et al., 1999). Animal models for different types of dystonia are rare. Clearly defined animal models of paroxysmal dyskinesias are still restricted to the genetically dystonic hamster (Richter and Löscher, 1998). The $d t^{\mathrm{sz}}$ mutant hamster shows all of the phenotypic features of a type of idiopathic paroxysmal dystonia in humans, characterized by long-lasting attacks of generalized dystonia that can be provoked by stress and caffeine (Demirkiran and Jankovic, 1995; Richter and Löscher, 1998).

The dystonic syndrome in $d t^{\mathrm{sz}}$ mutants shows an age-dependent time course, with the first occurrence observed at approximately day 16 of life. The severity of dystonia reaches a maximum at an age of 30-40 d. Thereafter the severity slowly declines until a complete remission of the stress-inducible dystonic attacks occurs at the age of $\sim 10$ weeks (Richter and Löscher, 1993). The age dependence of paroxysmal dystonia provides the possibility to examine the importance of changes in the pathogenesis of dystonia by ontogenetic studies (i.e., alterations detected at an age of maximum severity should be reduced or should even disappear in older animals after spontaneous remission of stress-inducible attacks). Previous ontogenetic studies indicated that striatal GABAergic disinhibition plays a critical role in the pathogenesis of dystonia in this animal model (Löscher and Hörstermann,

Received Jan. 31, 2001; revised April 17, 2001; accepted April 19, 2001.

This work was supported by Grants Ge 1103/1-1 and Ri 845/1-1 from the Deutsche Forschungsgemeinschaft. We thank Dr. M. Hamann, C. Bartling, and M. Weißing for their technical assistance.

Correspondence should be addressed to Dr. Angelika Richter at the above address. E-mail: arichter@pharma.tiho-hannover.de.

Copyright (C) 2001 Society for Neuroscience 0270-6474/01/210001-04\$15.00/0
1992; Richter and Löscher, 1993; Pratt et al., 1995; Burgunder et al., 1999). Recently, extracellular single unit recordings demonstrated dramatically reduced neuronal activity in the entopeduncular nucleus (EPN), the homolog of the internal segment of the globus pallidus in primates, in $d t^{\mathrm{sz}}$ mutants at the most sensitive age of dystonia. This alteration is probably based on a deficiency of striatal GABAergic interneurons (Gernert et al., 2000). In the present study, entopeduncular activity was examined in animals that had completely lost their susceptibility to stress-inducible dystonic attacks, to clarify whether the decreased basal ganglia output is essential for the expression of paroxysmal dystonia in this rodent model.

\section{MATERIALS AND METHODS}

Animals. The experiments were performed in male and female $d t^{\mathrm{sz}}$ mutant Syrian hamsters that were obtained by selective breeding as described in detail previously (Löscher et al., 1989). As in recent examinations (Gernert et al., 1999a,b, 2000), the age- and sex-matched nondystonic control hamsters used in the present study were obtained by breeding pairs of an outbred line that were provided by a commercial breeder (Central Institute for Laboratory Animal Breeding, Hannover, Germany). All dystonic and control hamsters were born and kept under the same controlled environmental conditions. All experiments were done in compliance with the German Animal Welfare Act.

This article is published in The Journal of Neuroscience, Rapid Communications Section, which publishes brief, peerreviewed papers online, not in print. Rapid Communications are posted online approximately one month earlier than they would appear if printed. They are listed in the Table of Contents of the next open issue of JNeurosci. Cite this article as: JNeurosci, 2001, 21:RC153 (1-4). The publication date is the date of posting online at www.jneurosci.org.

http://www.jneurosci.org/cgi/content/full/5384 

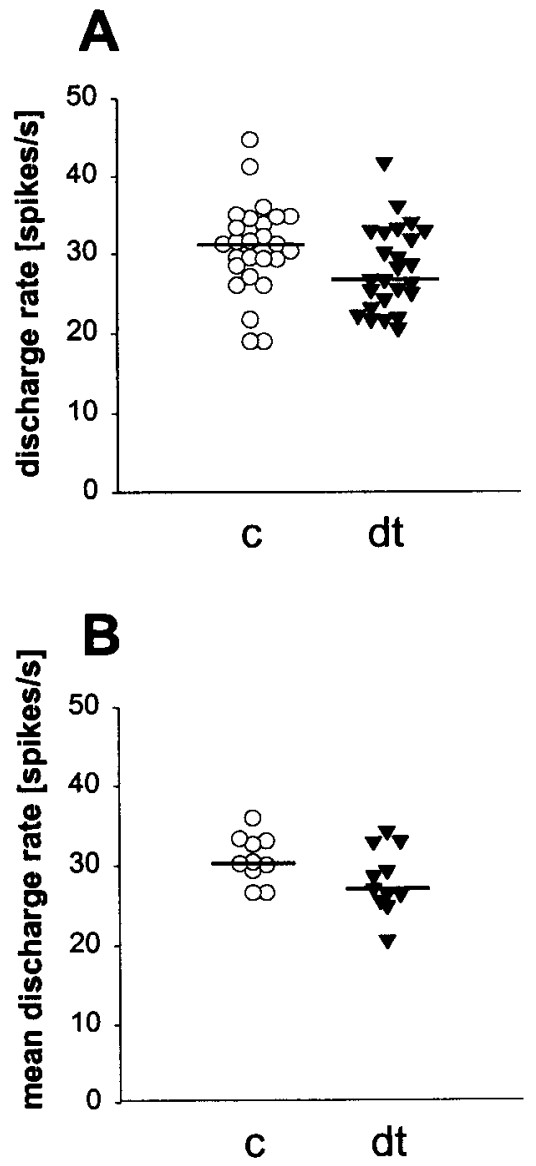

Figure 1. Spontaneous discharge rates of entopeduncular neurons recorded extracellularly and averaged over $10-15 \mathrm{~min}$ of recording time from 11 dystonic animals $(d t)$ and 10 nondystonic control hamsters $(c)$. The symbols represent the average discharge rate of each neuron $(A)$ or of one to four neurons per animal $(B)$. Medians are shown as horizontal lines.

Induction of dystonic attacks and severity score of dystonia. Motor impairments in $d t^{\mathrm{sz}}$ hamsters show the characteristics of human primary paroxysmal nonkinesiogenic dystonia (paroxysmal dystonic choreoathetosis) (Richter and Löscher, 1998). In $d t^{\mathrm{sz}}$ mutants, long-lasting dystonic attacks can be reproducibly induced by a triple stimulation technique (Löscher et al., 1989; Richter and Löscher, 1998) [i.e., stressful stimuli consisting of (1) taking the animal from its home cage and placing it on a balance, (2) injection of saline, and (3) placement of the animal in a new plastic cage]. After this procedure, $d t^{\mathrm{sz}}$ hamsters exhibit a pattern of abnormal movements and postures. Therefore, the severity of dystonia can be rated by a six-point score system (Löscher et al., 1989). In the present study, all mutant hamsters and control hamsters were examined for the presence of dystonia at the age of $21,32,90$, and $100 \mathrm{~d}$ by the triple stimulation procedure. Only $d t^{\mathrm{sz}}$ hamsters that showed the typical age-dependent time course (i.e., severe dystonia at an age of 21 and $30 \mathrm{~d}$ and a remission on days 90 and 100) were used for single unit recordings. Motor impairments were absent in control animals.

Single unit recordings within the EPN. The experiments were performed in groups of $16 d t^{\mathrm{sz}}$ hamsters and 14 control hamsters at an age of $123-152 \mathrm{~d}$. A total of $11 d t^{\mathrm{sz}}$ hamsters and 10 control animals that fulfilled the criteria of correct location of electrodes and electrophysiological characteristics of recorded neurons were used for final evaluations. The spontaneous firing rate of single neurons of the EPN was examined by extracellular single unit recordings using standard techniques, as described previously (Gernert et al., 2000). Briefly, the hamsters received methohexital (55 mg/kg, i.p.; Lilly, Gießen, Germany) and the opioid analgesic fentanyl ( $0.05 \mathrm{mg} / \mathrm{kg}$, i.p.; Janssen, Neuss, Germany) for anesthesia during surgical preparations (tracheotomy, vagotomy, and cannulation of the vena jugularis). The animals were ventilated with $\mathrm{O}_{2} /$ room air (rate $60-70 / \mathrm{min}$; tidal volume $0.8-2 \mathrm{ml}$ ) to maintain an expired $\mathrm{CO}_{2}$ level of 2-3\% as measured with a $\mathrm{CO}_{2}$ gas analyzer. After all surgical procedures, a bolus of gallamine $(30 \mathrm{mg} / \mathrm{kg}$, i.p.; Sigma, Diesenhofen, Germany) was given. Throughout the recordings, the animals received an infusion of gallamine $\left(15 \mathrm{mg} \cdot \mathrm{kg}^{-1} \cdot \mathrm{hr}^{-1}\right)$ and fentanyl $\left(0.05 \mathrm{mg} \cdot \mathrm{kg}^{-1} \cdot \mathrm{hr}^{-1}\right)$. Previous experiments in rodents have shown that this anesthesia does not alter the spontaneous activity of neurons within basal ganglia nuclei (Löscher et al., 1995; Gernert et al., 1999b). During the experiments, heart rate and body temperature were continuously monitored.

A single-barrel glass microelectrode filled with horseradish peroxidase in Tris-buffered saline was lowered to the EPN through a small burr hole in the skull. The stereotaxic coordinates of the EPN in millimeters relative to bregma [according to the method of Paxinos and Watson (1986)] were determined experimentally: posterior, 0.3; lateral, 2.2; ventral, 6.0. The electrode was slowly lowered under continuous recording of extracellular neural signals until a spontaneously active EPN neuron could be identified. When possible, several neurons per animal were recorded. Standard techniques for amplifying, discriminating, and processing an extracellular single unit action potential were used by means of the DataWave System (WissTech, Spechbach, Germany). After a stable EPN neuron with electrophysiological characteristics of GABAergic neurons was identified, the spontaneous discharge rate was monitored and averaged over 10-15 min. In both groups, recordings on EPN neurons were started at least $80 \mathrm{~min}$ after the last injection of the short-acting barbiturate methohexital.

As described recently (Gernert et al., 2000), the location of the electrode tip was marked by microiontophoretic injection of a small amount of horseradish peroxidase at the end of each experiment. After staining with horseradish peroxidase, the location of the recording electrodes could be verified according to the stereotaxic atlas of the golden hamster brain (Knigge and Joseph, 1968). Only neurons with an electrode location in the EPN that was $7.5-7.8 \mathrm{~mm}$ relative to interaural zero were used for further evaluation of data.

The spontaneous discharge rates of EPN neurons were averaged per neuron (10-15 min) and per animal. The statistical significance of the differences between the medians of these averaged activities of the mutant and the control group was calculated using the Mann-Whitney $U$ test; intergroup differences of the means were calculated using the $t$ test.

Table 1. Discharge rates of neurons of the entopeduncular nucleus in $d t^{\mathrm{sz}}$ mutant and nondystonic control hamsters

\begin{tabular}{llll} 
Age $(\mathrm{d})$ & $d t^{\mathrm{sz}}$ & Control $(\mathrm{c})$ & $p$ \\
\hline $123-152$ & $28.1 \pm 1.2(25 / 11)$ & $30.8 \pm 0.9(26 / 10)$ & $\begin{array}{l}d t^{\mathrm{sz}} \text { versus c }(-8.8 \%) \text { n.s. } \\
\end{array}$ \\
& $\begin{array}{l}d t^{\mathrm{sz}} \text { versus } d t^{\mathrm{sz}} \max (+72.6 \%)<0.0001 \\
c \text { versus c max }(+18.5 \%) \text { n.s. }\end{array}$ \\
$32-42$ (max.) & $7.7 \pm 1.5(30 / 15)$ & $25.1 \pm 3.2(36 / 16)$ & $d t^{\mathrm{sz}} \max$ versus c max $(-69.5 \%)<0.0001$
\end{tabular}

Discharge rates were assessed when hamsters were 123-152 d of age (after remission of dystonia in mutant hamsters) and were compared with the neuronal activity previously determined by using the same methods (Gernert et al., 2000) in younger animals (32-43 d; max, age of maximum severity of dystonia in $d t^{\mathrm{sz}}$ mutants). In all groups, the firing rates of single recorded neurons were averaged over 10-15 min of recording time and were then averaged per animal. The data are shown as means $\pm \mathrm{SE}$ (spikes/sec) of the averaged discharge rates of the different animal groups (number of neurons/number of animals). Relative increases $(+\%)$ or decreases $(-\%)$ of discharge rates are indicated. 


\section{RESULTS}

In vivo extracellular single unit recordings showed that the average firing rate of entopeduncular neurons in $d t^{\mathrm{sz}}$ hamsters was comparable with that of nondystonic controls (Fig. 1). The mean $( \pm \mathrm{SE})$ of the averaged discharge rates per animal was $28.1 \pm 1.2$ spikes/sec of 25 neurons in 11 mutant hamsters versus $30.8 \pm 0.9$ spikes/sec of 26 neurons in 10 control hamsters (Table 1). All recorded neurons in the entopeduncular nucleus of dystonic hamsters and control animals exhibited the electrophysiological characteristics of GABAergic neurons of basal ganglia output structures, as described previously (Gernert et al., 2000) (i.e., smooth, sharp, biphasic action potentials with a duration of $0.6-1.5 \mathrm{msec}$ ).

In comparison with recent data on the entopeduncular activity in animals at an age of 32-42 d (Gernert et al., 2000), determined by the same method used in the present study, the discharge rate of entopeduncular neurons was significantly increased in older $d t^{\mathrm{sz}}$ mutants $(p<0.0001)$, whereas no significant age-dependent changes were evident in control animals (Table 1).

\section{DISCUSSION}

The present single unit recordings in the hamster model demonstrate that the mean discharge rates of neurons of the EPN, recently detected to be significantly reduced in $d t^{\mathrm{sz}}$ hamsters the age at which the most marked expression of dystonia is usually observed (Table 1) (Gernert et al., 2000), reached normal levels after spontaneous remission of stress-inducible dystonic attacks in this animal model. In mutant hamsters, the lowered EPN activity is not secondary to the motor disturbances, because these changes were found to occur in the absence of dystonic attacks (Gernert et al., 2000). The present finding clearly supports the functional relevance of a decreased basal ganglia output for the expression of paroxysmal dystonia (i.e., the underactivity of entopeduncular neurons is not merely an epiphenomenon).

The existence of various phenotypic and genotypic subtypes indicates a heterogeneous pathogenesis of idiopathic dystonias, but different primary defects in humans may result in common neural disturbances (Wichmann and DeLong, 1996). Dystonias have been suggested to be related to lowered discharge rates of pallidothalamic neurons, because a reduced activity of GABAergic neurons in the medial segment of the globus pallidus (the EPN in rodents) was found in dystonic patients in comparison with patients with Parkinson's disease (Vitek et al., 1999). Together with recent findings in $d t^{\mathrm{sz}}$ mutants (Gernert et al., 2000), the present data provide the first direct evidence for this hypothesis. The $d t^{\mathrm{sz}}$ hamster represents a unique rodent model in which inborn dystonic movements are related to basal ganglia dysfunctions (Richter and Löscher, 1998; Gernert et al., 2000). However, iatrogenic dyskinesias (dystonia and chorea), provoked by chronic treatment with dopamine receptor agonists in Parkinsonian monkeys, are probably also related to an increased inhibition of the medial globus pallidus via the direct pathway (Mitchell et al., 1990; Crossman and Brotchie, 1998). In accordance with these observations and with the present data, case reports indicated that stimulation of the medial globus pallidus in patients with permanent dystonias exerts beneficial effects (Loher et al., 2000; Tronnier and Fogel, 2000). In contrast to these reports and to the finding of age-dependent entopeduncular underactivity in dystonic hamsters, a medial globus pallidus lesion can improve permanent and paroxysmal dystonias in patients (Bhatia et al., 1998; Ondo et al., 1998). An attempt to explain this paradox is that an abnormal irregular burst or grouped pattern of discharge, as detected in the medial globus pallidus of three patients with idiopathic generalized dystonia, could be more important than the decrease of the absolute firing rate (Wichmann and DeLong, 1996; Vitek et al., 1999; Vitek and Giroux, 2000). In $d t^{\mathrm{sz}}$ mutants, a comprehensive ontogenetic study of the patterns of entopeduncular and nigral neurons by interspike interval histogram analyses, initiated by the present finding, is under way. Furthermore, the present data encourage examination of the effects of EPN neurolesions and stimulations on the severity of dystonia in this animal model.

The EPN receives major GABAergic afferents via the monosynaptic striato-entopeduncular projection (Parent and Hazrati, 1995; Chesselet and Delfs, 1996). As shown by previous examinations, a reduced entopeduncular activity in $d t^{\mathrm{sz}}$ mutants at the age of the manifestation of severe dystonic attacks is probably based on an ontogenetic GABAergic disinhibition of striatoentopeduncular GABAergic projection neurons (Löscher and Hörstermann, 1992; Richter and Löscher, 1993; Gernert et al., 2000). Thus, a deficit of striatal GABA levels (Löscher and Hörstermann, 1992) and an enhanced activity of GABAergic striatal projection neurons (Gernert et al., 1999a) were found in mutant hamsters at the most sensitive age. These changes completely disappeared in $d t^{\mathrm{sz}}$ mutants that had lost their susceptibility to dystonia, which can explain the present finding of a normalization of the entopeduncular activity in the hamster model after spontaneous remission of dystonia. Ongoing immunohistochemical examinations of striatal parvalbumin-reactive interneurons in mutant hamsters at different ages have to clarify whether the recovery of entopeduncular activity after agedependent remission of dystonia is related to a disappearance of the deficiency of these GABAergic interneurons, recently found in young $d t^{\mathrm{sz}}$ hamsters that exhibited severe dystonia (Gernert et al., 2000).

\section{REFERENCES}

Bhatia KP, Marsden CD, Thomas DGT (1998) Posteroventral pallidotomy can ameliorate attacks of paroxysmal dystonia induced by exercise. J Neurol Neurosurg Psychiatry 65:604-605.

Burgunder J-M, Richter A, Löscher W (1999) Expression of cholecystokinin, somatostatin, thyrotropin-releasing hormone, glutamic acid decarboxylase, and tyrosine hydroxylase genes in the central nervous motor systems of the genetically dystonic hamster. Exp Brain Res 129:114-120.

Chesselet M-F, Delfs JM (1996) Basal ganglia and movement disorders: an update. Trends Neurosci 19:417-422.

Crossman AR, Brotchie JM (1998) Pathophysiology of dystonia. In: Advances in neurology, Dystonia 3, Vol 78 (Fahn S, Marsden CD, DeLong MR, eds), pp 19-25. New York: Lippincott-Raven.

Demirkiran M, Jankovic J (1995) Paroxysmal diskinesias: clinical features and classification. Ann Neurol 38:571-579.

Gernert M, Richter A, Löscher W (1999a) Alterations in spontaneous single unit activity of striatal subdivisions during ontogenesis in mutant dystonic hamsters. Brain Res 821:277-285.

Gernert M, Richter A, Löscher W (1999b) In vivo extracellular electrophysiology of pallidal neurons in dystonic and nondystonic hamsters. J Neurosci Res 57:894-905.

Gernert M, Hamann M, Bennay M, Löscher W, Richter A (2000) Deficit of striatal parvalbumin-reactive GABAergic interneurons and decreased basal ganglia output in a genetic rodent model of idiopathic paroxysmal dystonia. J Neurosci 20:7052-7058.

Knigge KM, Joseph SA (1968) A stereotaxic atlas of the brain of golden hamster. In: The golden hamster-its biology and use in medical research (Hoffman RA, Robinson PF, Magalhaes H, eds), pp 284-319. Ames, IA: Iowa State UP.

Loher TJ, Hasdemir MG, Burgunder JM, Krauss JK (2000) Long-term follow-up study of chronic globus pallidus internus stimulation for posttraumatic hemidystonia. J Neurosurg 92:457-460.

Löscher W, Hörstermann D (1992) Abnormalities in amino acid neurotransmitters in discrete brain regions of genetically dystonic hamsters. J Neurochem 59:689-694.

Löscher W, Fisher Jr JE, Schmidt D, Fredow G, Hönack D, Iturrian W B (1989) The $s z$ mutant hamster: a genetic model of epilepsy or of paroxysmal dystonia? Mov Disord 4:219-232. 
Löscher W, Rohlfs A, Rundfeldt C (1995) Reduction in firing rate of substantia nigra pars reticulata by valvroate: influence of different types of anesthesia in rats. Brain Res 702:133-144.

Mitchell IJ, Luquin R, Boyce CE, Robertson RG, Sambrook MA, Crossman AR (1990) Neural mechanisms of dystonia: evidence from a 2-deoxyglucose uptake study in a primate model of dopamine agonistinduced dystonia. Mov Disord 5:49-54.

Ondo WG, Desalom M, Jankovic J, Grossmann RG (1998) Pallidotomy for generalized dystonia. Mov Disord 13:693-698.

Parent A, Hazrati L-N (1995) Functional anatomy of the basal ganglia. I. The cortico-basal ganglia-thalamo-cortical loop. Brain Res Rev 20:91-127.

Paxinos G, Watson C (1986) The rat brain in stereotaxic coordinates. Sydney: Academic.

Pratt DG, Möhler H, Richter A, Löscher W (1995) Regionally selective and age-dependent alterations in benzodiazepine receptor binding in the genetically dystonic hamsters. J Neurochem 64:2153-2158.
Richter A, Löscher W (1993) Alterations in pharmacological sensitivity on GABAergic but not dopaminergic and glutaminergic systems during ontogenesis in dystonic mutant hamsters. Eur J Pharmacol 231:111-119.

Richter A, Löscher W (1998) Pathophysiology of idiopathic dystonia: findings from genetic animal models. Prog Neurobiol 54:633-677.

Tronnier VM, Fogel W (2000) Pallidal stimulation for generalized dystonia: report of three cases. J Neurosurg 92:453-456.

Vitek JL, Giroux M (2000) Physiology of hypokinetic and hyperkinetic movement disorders: model for dyskinesia. Ann Neurol 47:131-140.

Vitek JL, Chockkan V, Zhang J, Kaneoke Y, Evatt M, Mewes K, DeLong MR, Triche S, Mewes K, Hashimoto T, Bakay RA (1999) Neuronal activity in the basal ganglia in patients with generalized dystonia and hemiballismus. Ann Neurol 46:22-35.

Wichmann T, DeLong MR (1996) Functional and pathophysiological models of the basal ganglia. Curr Opin Neurobiol 6:751-758. 